\title{
Multitemporal Landsat Imagery with Optimum Band Ratio Techniques for Deciduous Forest Classification
}

\author{
Paengwangthong, $\mathrm{W}^{1,2^{*}}$ \\ ${ }^{1}$ Geographic Information Science, School of Information and Communication Technology, \\ University of Phayao, Phayao, 56000, Thailand, E-mail: wipop_p@hotmail.com \\ ${ }^{2}$ Research Unit of Spatial Innovation Development, School of Information and Communication Technology \\ University of Phayao, Phayao, 56000, Thailand
}

\begin{abstract}
The objective of the study is to evaluate optimum band ratio combinations data set derived from monthly Landsat 8 imageries for forest type classification around the Sirikit dam reservoir using supervised classification with Maximum Likelihood Classifier (MLC). In this study, imageries data acquired from January 2014 to November 2017 were used to create the monthly band ratio data set of Normalized Difference Vegetation Indices (NDVI), Normalized Difference Moisture Indices (NDMI), and Normalized Burn Ratios (NBR) and used to create the monthly multispectral (MS) data set represented as a case of without applying band ratio techniques. In classifying deciduous forest type, four data sets were used to classify two classes of deciduous forests, namely mixed deciduous forest and dry deciduous dipterocarp forest. After the accuracy assessment, the result showed that the overall accuracy and kappa coefficient of all data sets were between $78.33 \%-86.21 \%$ and between $44.32 \%-62.83 \%$, respectively. Herein, the monthly NDVI multitemporal data set provided the highest overall accuracy and kappa coefficient which were better than the monthly MS multitemporal data set about 4\% and 8\%, respectively. In conclusion, applying monthly multitemporal data of Landsat 8 with band ratio technique, especially NDVI, can increase the accuracy of deciduous forest type classification.
\end{abstract}

\section{Introduction}

Deciduous forest in Thailand can be divided into 2 types, including mixed deciduous forest and dry deciduous dipterocarp forest. Both of them were the dominant forest type ( $70 \%$ of all forests) that benefit people directly and indirectly. Forests are not only for wood, food and medicines but are also head of a watershed area, biodiversity habitats and recreation area (Sungpalee, 2002). To ensure that these services are maintained, forest resources management and monitoring are important programs done by the Royal Forest Department (RFD) and Department of National Parks, Wildlife, and Plant Conservation (DNP) in Thailand (Boonyasap, 2011 and FLM, 2019).

Remote Sensing has been popular as a tool for forest area monitoring and classification because of its ability to cover a large area without data collection from the ground and thus saves cost and time (Klaydach, 2013). The revolution of forest type classification in the country began from visual interpretation, unsupervised and supervised classification, respectively (Wichawutipong, 2006). However, currently, many techniques were developed i.e. texture analysis, object-based classification, and phenology-based classification.
According to previous studies, phenology-based land cover classification with multitemporal imageries tends to become popular particularly in vegetation coverage and dynamics such as forest and agricultural area (Kongseng, 2017, Oliveira, 2009, Patakamuria et al., 2014 and Simonetti et al., 2014), since its image point data value change according to time condition and vegetation characteristics. For example, phenological characteristics of vegetations within dry deciduous dipterocarp forest adapt according to seasonal changes where leaves fall off during the dry season and bloom in the rainy season (Patakamuria et al., 2014). There are several unique identity aids to increase the accuracy of forest type classification. However, studying and using multitemporal satellite imageries for deciduous forest classification is still limited in the country. As an example, the study of Paengwangthong (2018) suggested that there are many points such as different input data set that give opportunities for further study. Moreover, there is an interesting difference between multitemporal data with and without band ratio techniques that can identify the optimum band ratio combinations data set for deciduous forest type classification. 
Due to the need for accurate forest type classification, a different approach could provide a simple but effective tool for forest monitoring and management. Thus, this study aims to classify deciduous forest type by Maximum Likelihood Classifier (MLC) using 4 input monthly imageries data set i.e. monthly multitemporal of Normalized Difference Vegetation Indices (NDVI), Normalized Difference Moisture Indices (NDMI), Normalized Burn Ratios (NBR), and multispectral data (MS). Comparisons of the overall accuracy and kappa coefficient of all data sets are then performed to provide the basis for deciding the appropriate input monthly imageries data sets for classifying the deciduous forest type. Moreover, the surrounding area of the Sirikit dam reservoir was selected as the study area because of its vastness and fullness as a prototype. It resembles several deciduous forests of the country. At the same time, the study can also be used to support officials in forest monitoring and management.

\section{Study Area}

Sirikit dam reservoir is located at the watershed head area of Nan River and covers a total area of around 250 square kilometres (Fishsiam, 2019). The deciduous forest surrounding it was chosen as the study area (Figure 1) which is situated between the southern part of Phare Province and the northern part of Phitsanulok Province with latitudes between $17^{\circ} 29^{\prime} 55^{\prime \prime}$ to $18^{\circ} 10^{\prime} 10^{\prime \prime} \mathrm{N}$ and longitudes between $100^{\circ} 10^{\prime} 30^{\prime \prime}$ to $100^{\circ} 50^{\prime} 15^{\prime \prime} \mathrm{E}$.

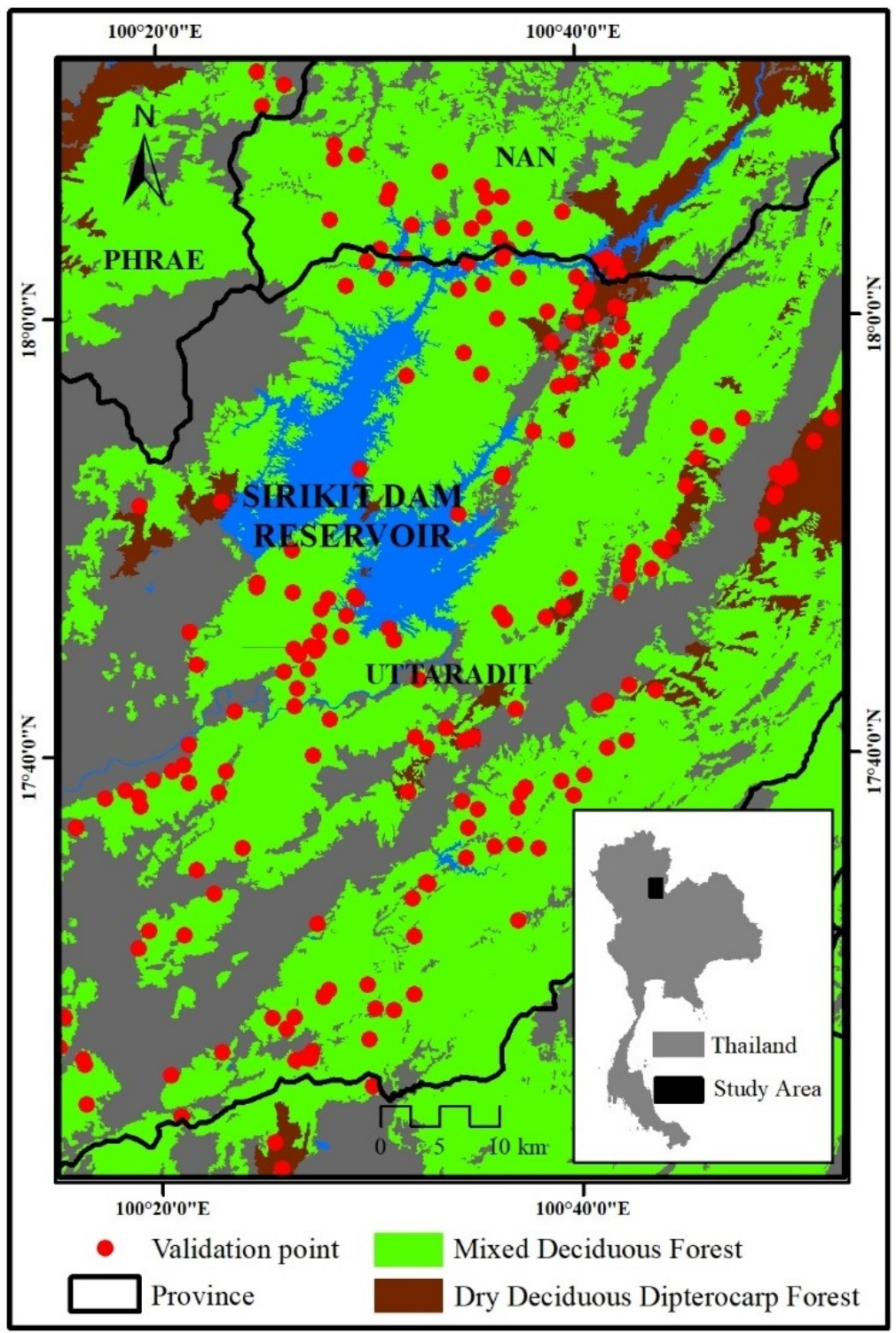

Figure 1: Location of the study area and the distributions of validation points 
The deciduous forest is protected and declared as a conservation area. Within the area of the reservoir are a national park and wildlife sanctuary i.e. Lamnam Nan National Park, Khun Sathan National Park, Sri Nan National Park, Khlong Tron National Park, Lam Nam Nan Fang Khwa Wildlife Sanctuary, and Maecharim Wildlife Sanctuary. The classified mixed deciduous forest is dominated by hardwoods i.e. Teak, Ironwood, Burma Padauk, and Afzelia. The dry deciduous dipterocarp forest was identified to be dominated by Burma Sal, Burmese sal, Rubber, Broken bones and Morinda (ONP, 2020). As mentioned above, the variety of dominant trees has been rather a biodiversity.

\section{Methodology}

The research methods comprised the following: (1) preparing monthly multitemporal Landsat imageries, (2) Training area for classification and validation point, (3) Classification processing, and (4) accuracy assessment. The main steps of the study are illustrated in Figure 2.

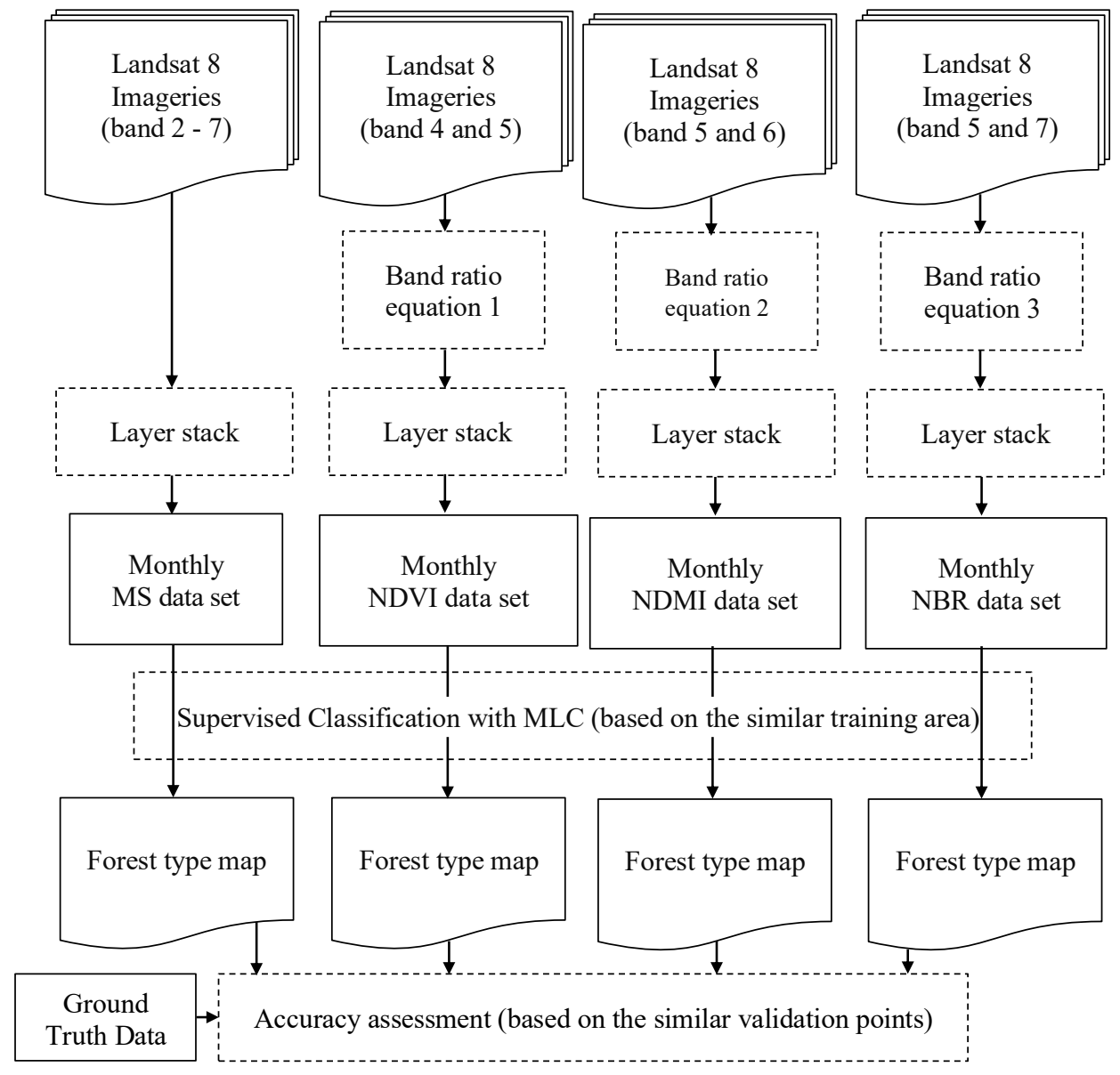

Figure 2: The study procedures

Table 1: Band specification of Landsat 8 OLI (USGS, 2017a)

\begin{tabular}{|c|l|}
\hline Band & \multicolumn{1}{|c|}{ Wavelength (Micron) } \\
\hline 2 & $0.45-0.51$ (Visible: Blue) \\
\hline 3 & $0.53-0.59$ (Visible: Green) \\
\hline 4 & $0.64-0.67$ (Visible: Red) \\
\hline 5 & $0.85-0.88$ (Near Infrared: NIR) \\
\hline 6 & $1.57-1.65$ (Shortwave Infrared: SWIR1) \\
\hline 7 & $2.11-2.29$ (Shortwave Infrared: SWIR2) \\
\hline
\end{tabular}


Table 2: Dates selected of Landsat 8 OLI data

\begin{tabular}{|l|c|c|c|c|c|}
\hline \multicolumn{7}{|c|}{ Dates Selected (DMY format) } \\
\hline $08 / 01 / 2014$ & $21 / 09 / 2014$ & $03 / 05 / 2015$ & $30 / 01 / 2016$ & $10 / 09 / 2016$ & $08 / 05 / 2017$ \\
\hline $09 / 02 / 2014$ & $23 / 10 / 2014$ & $20 / 06 / 2015$ & $15 / 02 / 2016$ & $28 / 10 / 2016$ & $25 / 06 / 2017$ \\
\hline $13 / 03 / 2014$ & $24 / 11 / 2014$ & $06 / 07 / 2015$ & $18 / 03 / 2016$ & $13 / 11 / 2016$ & $27 / 07 / 2017$ \\
\hline $14 / 04 / 2014$ & $26 / 12 / 2014$ & $23 / 08 / 2015$ & $03 / 04 / 2016$ & $31 / 12 / 2016$ & $12 / 08 / 2017$ \\
\hline $16 / 05 / 2014$ & $27 / 01 / 2015$ & $24 / 09 / 2015$ & $05 / 05 / 2016$ & $16 / 01 / 2017$ & $13 / 09 / 2017$ \\
\hline $01 / 06 / 2014$ & $28 / 02 / 2015$ & $26 / 10 / 2015$ & $22 / 06 / 2016$ & $01 / 02 / 2017$ & $31 / 10 / 2017$ \\
\hline $03 / 07 / 2014$ & $16 / 03 / 2015$ & $27 / 11 / 2015$ & $24 / 07 / 2016$ & $05 / 03 / 2017$ & $16 / 11 / 2017$ \\
\hline $20 / 08 / 2014$ & $17 / 04 / 2015$ & $13 / 12 / 2015$ & $9 / 08 / 2016$ & $22 / 04 / 2017$ & $02 / 12 / 2017$ \\
\hline
\end{tabular}

\subsection{Preparing Monthly Multitemporal Landsat Imageries}

Landsat 8 operational land imager (OLI) level-1 data product was downloaded from the USGS website (https://earthexplorer.usgs.gov/). It was already collected for both radiometric and geometric correction with 30-meter spatial resolution. Besides, Landsat 8 imageries data acquired from January 2014 to November 2017 were used by the condition of minimum cloud cover as monthly imagery data. Moreover, Band 2 to Band 7 (Table 1 and 2) were prepared for creating the monthly imageries data of NDVI, NDMI, NBR, and MS for further steps.

After satellite image data were downloaded, band ratio techniques were used to create NDVI, NDMI, and NBR data based on Equation 1, 2, and 3 , respectively. Then, the monthly multitemporal data set was combined respectively into a single file using layer stack command of ERDAS Imagine software. Corresponding with the later method, monthly MS data were also prepared without band ratio techniques but monthly band $2-7$ were combined into a single file using that same command. There are 3 band ratio techniques for this study i.e. NDVI, NDMI, and NBR. The details of each data can be calculated as the following mathematical expression (USGS, 2017b).

$$
\begin{gathered}
N D V I=N I R-R E D / N I R+R E D \\
\text { Equation } 1 \\
N D M I=N I R-S W I R 1 / N I R+S W I R 1 \\
\text { Equation } 2 \\
N B R=N I R-S W I R 2 / N I R+S W I R 2 \\
\text { Equation } 3
\end{gathered}
$$

where $N I R$ is the original input brightness value in the near-infrared band, $R E D$ is the original input brightness value in the red band and SWIR is the original input brightness value in the shortwave infrared band.

\subsection{Training Area for Classification and Validation Point}

Both training area and validation points used relied on the digital forest type layer of RFD. For the validation points, it has a total number of 203 points which were separated using stratified random sampling in ERDAS Imagine. There were 164 points for mix deciduous forest and 39 points for dry deciduous dipterocarp forest as seen in Figure 1. However, the number of validation points were more than the minimum point $(n=196)$ which is calculated relying on sample size based on binomial distribution probability theory (Fitzpatrick-Lins, 1981 ) as seen in the following equation.

$$
N=Z^{2} p q / E^{2}
$$

Equation 4

where $p$ is the expected per cent accuracy and $q$ is $100-p$ and $E$ is the allowable error. For the study, $Z$ $=2$ is generalized from the standard normal deviate of 1.96 for the $95 \%$ two side confidence level, $p=$ $85, q=15$ and $E=5$ (These parameter values were suggested by Fitzpatrick-Lins, 1981) Thus, $N=$ $(1.962 \times 85 \times 15) / 52$ or 196 points.

\subsection{Classification Processing}

Total monthly data set (i.e. MS, NDVI, NDMI, and NBR) with a similar training area were used alternately as input data for supervised classification by ERDAS Imagine. The whole study area was separated respectively into 2 discrete classes i.e. mix deciduous and dry deciduous dipterocarp forest. For the conception of MLC, there were measured parameters (mean and covariance matrix) of each training area then a pixel-based classification was done based on normal distribution theory. The probability of the individual image point was calculated and used to allocate that point to one of the discrete classes (Ongsomwang, 2016). 
.4 Accuracy Assessment

After classification processing, there were 4 thematic forest type maps compared together by accuracy assessment through parameters derived from error matrix (confusion matrix) as seen in Table 3 (Ongsomwang and Saraisamrong, 2017 and Story and Congalton, 1986) followed by a calculation of the overall accuracy and kappa coefficient of the thematic forest type maps as shown in Equation 5 and 6 (Jensen, 2005 and Story and Congalton, 1986). These imply the accuracy and agreement between the classification maps and the ground reference information, respectively (Ongsomwang, 2016).

$$
\text { overall accuracy }=\frac{\sum_{i=1}^{k} n_{i i}}{N}
$$

Equation 5

$$
\text { Khat }=\frac{N \sum_{i=1}^{k} n_{i i}-\sum_{i=1}^{k}\left(n_{i+} \times n_{+i}\right)}{N^{2}-\sum_{i=1}^{k}\left(n_{i+} \times n_{+i}\right)}
$$

Equation 6
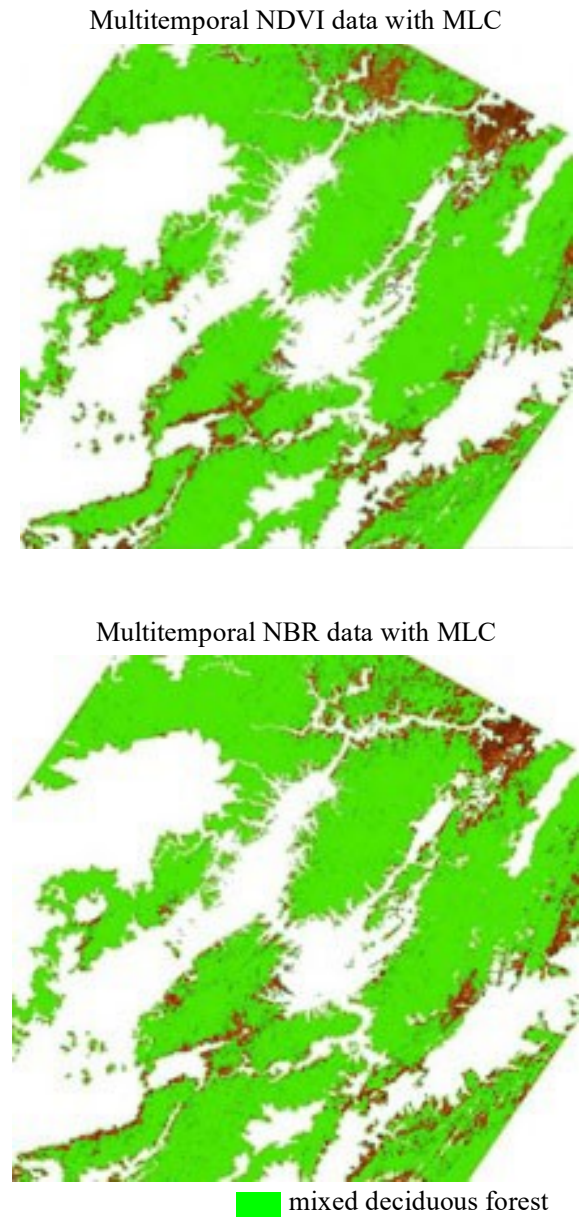

where $k$ is the number of rows (e.g. forest type classes), $n_{i i}$ is the number of the observation in row $\mathrm{i}$ and column i, $n_{i+}$ is the marginal totals for row i, $n_{+i}$ is the marginal totals for column $\mathrm{i}$, and $N$ is the total number of observations.

\section{Results and Discussion}

\subsection{Results}

Application of monthly multitemporal data of Landsat 8 with band ratio combination for deciduous forest classification with MLC can be labelled all image point into 2 classes of deciduous forest, including mixed deciduous forest and dry deciduous dipterocarp forest. There are 4 different band ratio techniques as an input data set e.g. NDVI, NDMI, NBR and MS with training area based on RFD data. The result of the classified forest map is presented in Figure 3. Accuracy assessment through overall accuracy and kappa coefficient was applied alternatively with all output map based on a similar total of 203 validation points.
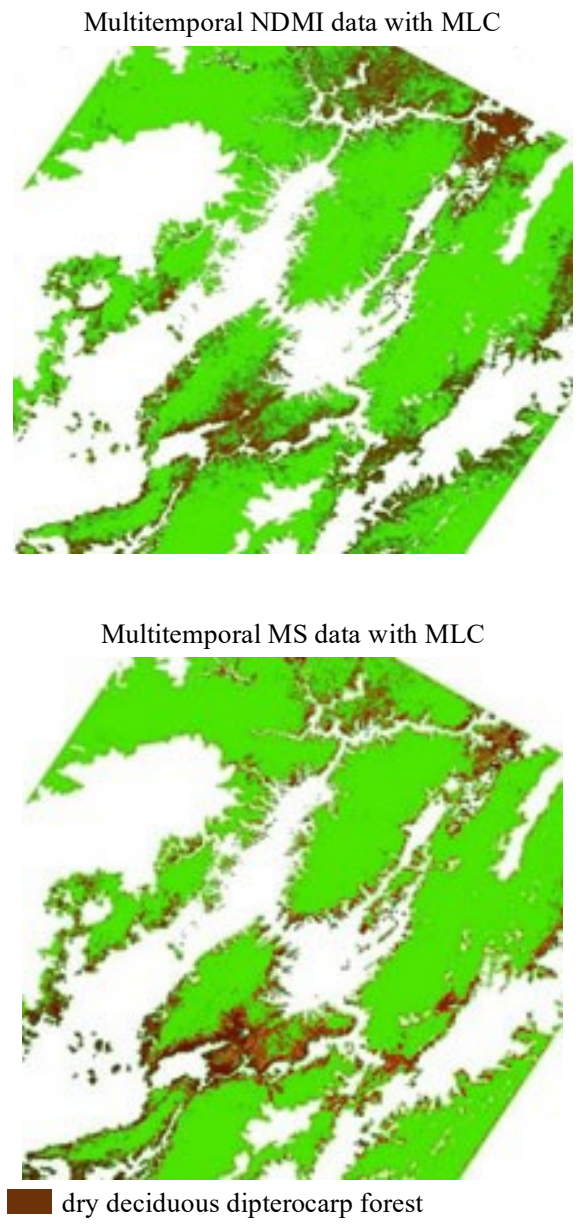

Figure 3: Classified forest type map 
Table 3: Characteristic of an error matrix

\begin{tabular}{|l|c|c|c|}
\cline { 2 - 4 } \multicolumn{1}{c|}{} & \multicolumn{3}{c|}{ Reference Data } \\
\hline Classified Data & Mixed Deciduous & Dry Deciduous & Row Total \\
\hline Mixed Deciduous & $n_{11}$ & $n_{12}$ & $n_{1+}$ \\
\hline Dry Deciduous & $n_{21}$ & $n_{22}$ & $n_{2+}$ \\
\hline Column Total & $n_{+1}$ & $n_{+2}$ & $N$ \\
\hline
\end{tabular}

Table 4: Error matrix and their accuracy assessment

Multitemporal NDVI data with MLC

\begin{tabular}{|l|c|c|c|}
\cline { 2 - 4 } \multicolumn{1}{c|}{} & \multicolumn{3}{c|}{ Reference Data } \\
\hline \multicolumn{1}{c|}{ Classified Data } & Mixed Deciduous & Dry Deciduous & Row Total \\
\hline Mixed Deciduous & 140 & 4 & 144 \\
\hline Dry Deciduous & 24 & 35 & 59 \\
\hline Column Total & 164 & 39 & 203 \\
\hline Overall accuracy (\%) & \multicolumn{3}{|c}{86.21} \\
\hline Kappa coefficient (\%) & \multicolumn{3}{|c}{62.83} \\
\hline
\end{tabular}

Multitemporal NBR data with MLC

\begin{tabular}{|l|c|c|c|}
\cline { 2 - 4 } \multicolumn{1}{c|}{} & \multicolumn{3}{c|}{ Reference Data } \\
\hline \multicolumn{1}{c|}{ Classified Data } & Mixed Deciduous & Dry Deciduous & Row Total \\
\hline Mixed Deciduous & 137 & 7 & 144 \\
\hline Dry Deciduous & 27 & 32 & 59 \\
\hline Column Total & 164 & 39 & 203 \\
\hline Overall accuracy (\%) & \multicolumn{3}{|c|}{83.25} \\
\hline Kappa coefficient (\%) & \multicolumn{3}{|c}{54.87} \\
\hline
\end{tabular}

The result showed that the overall accuracy and kappa coefficient of all data sets were between $78.33 \%-86.21 \%$ and between $44.32 \%-62.83 \%$, respectively. Herein, the monthly NDVI multitemporal data set provided the highest overall accuracy and kappa coefficient, these values were better than monthly MS multitemporal data set about $4 \%$ and $8 \%$, respectively as shown in (Table 4).

\subsection{Discussion}

Phenology-based classification, especially in high dense vegetation coverage using multitemporal satellite for at least 2 continuous years is enough for usage (Oliveira, 2009 and Paengwangthong, 2018). This research aimed at comparing parameters of accuracy and agreement of forest type classification by similar training, classifier, and validation point using different image input data set. However, MLC was used for the study since it has been the most accurate classifier and suitable for forest type classification in the country (Ongsomwang, 2016).

The result of this study shows that applying band ratio combination particularly NDVI can derive
Multitemporal NDMI data with MLC

\begin{tabular}{|l|c|c|c|}
\cline { 2 - 4 } \multicolumn{1}{c|}{} & \multicolumn{3}{c|}{ Reference Data } \\
\hline \multicolumn{1}{c|}{ Classified Data } & Mixed Deciduous & Dry Deciduous & Row Total \\
\hline Mixed Deciduous & 129 & 9 & 138 \\
\hline Dry Deciduous & 35 & 30 & 65 \\
\hline Column Total & 164 & 39 & 203 \\
\hline Overall accuracy (\%) & \multicolumn{3}{c|}{78.33} \\
\hline Kappa coefficient (\%) & \multicolumn{3}{c}{44.32} \\
\hline
\end{tabular}

Multitemporal MS data with MLC

\begin{tabular}{|l|c|c|c|}
\cline { 2 - 4 } \multicolumn{1}{c|}{} & \multicolumn{3}{c|}{ Reference Data } \\
\hline \multicolumn{1}{c|}{ Classified Data } & Mixed Deciduous & Dry Deciduous & Row Total \\
\hline Mixed Deciduous & 133 & 5 & 138 \\
\hline Dry Deciduous & 31 & 34 & 65 \\
\hline Column Total & 164 & 39 & 203 \\
\hline Overall accuracy (\%) & \multicolumn{3}{|c|}{82.27} \\
\hline Kappa coefficient (\%) & \multicolumn{3}{|c}{54.44} \\
\hline
\end{tabular}

higher accuracy than NDMI, NBR, and MS. Therefore, it can be mentioned that the monthly phenology of changing vegetation in the deciduous forest have more effect on accuracy, more than moisture and fire within a year cycle. It is corresponding with the study of Olivera (2009) and Patakamuria et al., (2014) which used NDVI multitemporal as input for deciduous forest classification as well. As above mentioned, Landsat 8 OLI was selected for the study because of the sufficiency of its temporal resolution which has a scene represented completely all of 3 seasonal cycle. It is corresponding with the study of Olivera (2009) and Wilson and Sader (2002) using Landsat 8 imagery as input for deciduous forest classification as well.

\section{Conclusions}

As a result of varying accuracy indicators, it can be confidently mentioned that applying monthly multitemporal NDVI data set aids more accuracy in determining deciduous forest type classification as compared with NDMI, NBR, and MS. The result can be used to improve the current study and policy 
implication for forest monitoring as a prototype or guide for similar forest characterization. For future study, identifying the optimum length of multitemporal data for a suitable forest classification with reasonable and acceptable accuracy should be considered. Secondly, other satellite data should be studied for forest type classification e.g. Sentinel, THEOS, ASTER, and MODIS. Finally, another land-cover classification with multitemporal data should also be studied in e.g. in urban and agricultural area.

\section{Acknowledgements}

The author would like to express appreciation to the anonymous reviewers for their valuable comments and contributions to the manuscript. The Royal Forest Department (RFD) and U.S. Geological Survey (USGS) is also acknowledged for providing the digital layer file of forest type and Landsat 8 imageries, respectively.

\section{References}

Boonyasap, N., 2011, Application of Remote Sensing and GIS to Analyze Forest Corridor and Forest Management Guidelines in The Eastern Forest Complex, (MSc.Thesis). Kasetsart University. Bangkok, Thailand, 117.

Fishsiam, 2019, Sirikit Dam Thailand, Available from. www.fishsaim.com.

Fitzpatrick-Lins, K., 1981, Comparison of Sampling Procedures and Data Analysis for a Land-use and Land-cover Map. Photogrammetric Engineering \& Remote Sensing, Vol. 47(3), 343351.

Forest Land Management Office (FLM), 2019, Final Report on Forest Area Survey Project, Royal Forest Department, Bangkok, 296. Available from: www.forest.go.th.

Jensen, J. R., 2005, Introductory Digital Image Processing: A Remote Sensing Perspective, (New Jersey: Prentice-Hall), 526.

Klaydach, T., 2013, Using of Vegetation Indices from Thaichote Satellite Data for Forest Types Classification in Doi Luang National Park, Chiang Rai Province, (MSc.Thesis). Kasetsart University, Bangkok, Thailand, 104.

Kongseng, P., 2017, Phenological based for Land Use and Land Cover Classification of Phuket Province using Landsat 8 OLI Imagery, (MSc.Thesis). Prince of Songkla University, Songkla, Thailand, 69.

Office of National Park (ONP), 2020, National Parks in Thailand, Available from. http://portal.dnp.go.th.
Oliveira, T. C. de A., 2009, Remote Sensing of Deciduous Forests: A Multi-Temporal Approach, (PhD. Thesis). Universidade Federal de Lavras, Brasil, 43.

Ongsomwang, S. and Saraisamrong, S., 2017, Pixelbased and Object-based Image Analysis Comparison for Land Use and Land Cover Classification. Journal of Remote Sensing and GIS Association of Thailand, Vol. 18(2-3), 1-22.

Ongsomwang, S., 2016, Remote Sensing System and Digital Image Analysis, School of Geoinformatics, Institute of Science, Suranaree University of Technology, Nakhon Ratchasima, 1009.

Patakamuria, S. K., Agrawal, S. and Krishnavenia, M., 2014, Time-Series Analysis of MODIS NDVI Data along with Ancillary Data for Land use/Land cover Mapping of Uttarakhand. The International Archives of the Photogrammetry, Remote Sensing and Spatial Information Sciences, XL-8(2014 ISPRS Technical Commission VIII Symposium): 1491-1500.

Paengwangthong, W., 2018, Classification of Deciduous Forest Area Using Multitemporal Landsat Imageries with Band Ratio Techniques. Thai Journal of Science and Technology, Vol. 26(8), 1302-1310.

Simonetti, E., Simometti, D. and Preatoni, D., 2014, Phenology-based Land Cover Classification Using Landsat 8 Time Series, (Technical Report). Joint Research Centre of the European Commission, 57.

Story, M. and Congalton, R., 1986, Accuracy Assessment: A User's Perspective. Photogrammetric Engineering \& Remote Sensing, Vol. 52(3), 397-399.

Sungpalee, W., 2002, Some Ecological Characteristics of Deciduous Forests along the Altitudinal Gradients in Doi Inthanon National Park, (MSc.Thesis). Kasetsart University, Bangkok, Thailand, 131.

U. S. Geological Survey (USGS), 2017a, Band Designations for Landsat Satellites, Available From: www.usgs.gov.

U.S.Geological Survey (USGS), 2017b, Landsat Spectral Indices Product Guide, Available From: www.usgs.gov.

Wichawutipong, J., 2006, Forest Area Monitoring in Thailand with the use of Satellite Imagery. Available From: www.unoosa.org.

Wilson, E. H. and Sader, S. A., 2002, Detection of Forest Harvest Type using Multiple Dates of Landsat TM Imagery. Remote Sensing of Environment, Vol. 80(3), 385-396. 